\title{
Type D Personality Is Associated with Glycemic Control and Socio-Psychological Factors on Patients with Type 2 Diabetes Mellitus: A Cross- Sectional Study
}

This article was published in the following Dove Press journal:

Psychology Research and Behavior Management

\author{
Yi-Hsin Lin $\mathbb{D}^{\prime}$ \\ Di-An Chen ${ }^{2}$ \\ Chemin $\operatorname{Lin} \mathbb{D}^{3}$ \\ Hsuan Huang ${ }^{4}$ \\ 'Division of Endocrinology and \\ Metabolism, Department of Internal \\ Medicine, Taiwan Adventist Hospital, \\ Taipei, Taiwan (R.O.C.); ${ }^{2}$ Department of \\ Clinic Psychology, Fu Jen Catholic \\ University, Taipei, Taiwan (R.O.C.); \\ ${ }^{3}$ Department of Psychiatry, Keelung Chang \\ Gung Memorial Hospital, Keelung, Taiwan \\ (R.O.C.); ${ }^{4}$ Division of Pediatric Surgery, \\ Department of Surgery, Mackay Memorial \\ Hospital, Taipei, Taiwan (R.O.C.)
}

Purpose: Type D personality (TDP) has been recognized as a risk factor for many diseases. The aims of our study were to estimate the prevalence of TDP and glycemic control on the patients with type 2 diabetes mellitus (T2DM) and to assess their relationship between TDP and socio-psychological factors, such as perceived stress, self-efficacy, self-care behaviors, and psychological distress.

Patients and Methods: A total of 198 T2DM patients (male 62.6\%, mean age 51.2 \pm 11.0 , mean $\mathrm{HbA} 1 \mathrm{c} 7.3 \pm 1.8 \%$ ) were recruited consecutively from the Department of Endocrinology of a regional hospital in Taipei, Taiwan, from December 2017 to April 2018. They completed questionnaires that contain questions about sociodemographic characteristics, TDP, illnessrelated stress, self-efficacy, execution of diabetes management and emotional distress. Their medical records were reviewed for biomedical data.

Results: Of the 198 patients, $82(41.4 \%)$ had TDP. Controlling for sociodemographic factors, patients with TDP were reported significantly poorer on glycemic control than those without TDP (mean HbA1c (\%) 7.6 \pm 1.9 vs $7.1 \pm 1.8, P<0.05$ ). Compared to those without TDP, the results showed significantly higher levels of perceived stress $(P<0.001)$ and psychological distress (anxiety and depression) $(P<0.001)$, as well as significantly lower levels of self-efficacy $(P<0.001)$ and self-care behaviors $(P<0.001)$ on patients with TDP. TDP was positively correlated with perceived stress and psychological distress and negatively correlated with self-efficacy and self-care behaviors scores.

Discussion: This study provides the evidence linking TDP with poor glycemic control, low levels of self-efficacy and self-care behaviors, as well as high levels of perceived stress and psychological distress, which highlights the screening of TDP and the tailored needs for the care among T2DM patients with TDP.

Keywords: Type D personality, type 2 diabetes mellitus, perceived stress, self-efficacy, self-care behaviors, psychological distress

\section{Introduction}

Among different personality traits, Type D personality (TDP) is defined that individuals simultaneously experience high levels of two personality traits, negative affectivity (NA) and social inhibition (SI). NA is the tendency to experience negative emotions across time and situations, while SI is the tendency of the selfexpression emotion inhibitor for the fears of others' reactions during social interactions. ${ }^{1-3}$ TDP can be assessed by means of a valid and reliable questionnaire,
Correspondence: Hsuan Huang Department of Surgery, Mackay Memorial Hospital, Taipei, Taiwan (R.O.C.) Tel +886-2-2562-7200

Emailsmilefortw@hotmail.com 
the Type D Scale (DS14), which consists of two 7-item subscales to measure NA and $\mathrm{SI}^{2}{ }^{2}$

TDP is considered as a psychological risk factor in many diseases. Existing pieces of evidence showed that standard biomedical risk factors, such as blood pressure, cholesterol level, obesity and poor cardiovascular outcome, are significantly related to TDP. ${ }^{4-8}$ TDP also affects clinical factors and poor prognosis in patients with diabetes. ${ }^{9}$

Nefs G et al reported the prevalence of TDP was $29 \%$ on Dutch adults with diabetes. ${ }^{10}$ T2DM patients with TDP experienced less social support but more stressful life events, loneliness, depressed mood, anhedonia, and anxiety. ${ }^{11-13}$ Milicevic et al discovered that T2DM patients with TDP were less compliant about visits to primary-care physicians. ${ }^{14} \mathrm{Li}$ et al found that TDP had poor medication adherence, associated with high HbA1c levels on T2DM patients. ${ }^{15,16}$ Shao et al described T2DM patients with TDP were associated with lower levels of self-efficacy, social support and poor glycemic control. ${ }^{17}$ It is suggested that TDP needs special clinical attention to psychological assessment and treatment to prevent potential negative clinical outcomes. ${ }^{18}$

It is known that socio-psychological factors, such as self-efficacy, self-care behaviors, perceived stress, and psychological distress play important roles in psychological aspects of diabetes care. Self-efficacy is defined as the belief in one's capabilities to organize and execute the courses of action that are required to produce the given achievement. ${ }^{19}$ Strong self-efficacy has been associated with better self-management behaviors in diabetes, including the control of dietary habits, exercise, blood glucose testing, and medication compliance. ${ }^{20,21}$ Poor self-efficacy has been associated with increased depressive symptoms and poor glycemic control. ${ }^{22}$ Obviously, self-efficacy affects glycemic control and the outcome of diabetes.

Diabetes is often accompanied by psychological distress and stress. There is a significantly higher prevalence of depression and anxiety on T2DM patients than the general population. ${ }^{23,24}$ Psychological distress affects treatment choices, self-management, and outcomes on these patients. ${ }^{25-27}$ Additionally, researches on T2DM individuals show that perceived stress disrupts diabetes control indirectly through effects on diet, exercise, and their self-care behaviors, which causes problems in the effective management of diabetes. ${ }^{28,29}$

The aims of our study were to estimate the prevalence of TDP on Taiwanese patients with T2DM, and also to assess the relationship between TDP and socio-psychological factors, such as perceived stress, self-efficacy, self-care behaviors, and psychological distress on these T2DM patients.

\section{Patients and Methods}

\section{Study Setting and Participants}

The study was approved by the ethics committee of the regional hospital. Participants who visited the endocrine clinics of the regional hospital in Taipei were recruited consecutively from the outpatients between December 2017 and April 2018. The participants were provided with both written consent and oral information regarding the study, who were also informed that they were free to withdraw from the study at any time. The study was conducted in accordance with the Declaration of Helsinki.

According to the diagnostic criteria of American Diabetes Association (2016), all the participants who were diagnosed as T2DM were at least 20 years of age and were receiving regular anti-diabetic treatment. Each one was willing and was able to complete the questionnaire. The following exclusion criteria were applied to the study in order to simplify the variants of the study: participants were having concurrent malignant tumors, type 1 or gestational diabetes, late stage of cardiovascular, renal diseases or acute complications, severe neurocognitive disorders or psychiatric illness (such as schizophrenia), and who were taking antidepressants.

\section{Data Collection}

Under the guidance of the trained hospital staff, the eligible participants were firstly asked to complete the structured questionnaire, that contained demographic and socioeconomic data in a quiet environment, and then fivescale questionnaires (TDP, self-efficacy, self-care behaviors, perceived stress and psychological distress scales). Each one completed the scales without mandatorily stipulated time. Their medical records were reviewed to obtain and confirm information on the medical history, treatment and present glycosylated hemoglobin (HbAlc) level in the past 3 months.

\section{Type D Personality}

TDP was assessed and diagnosed by using Type D Scale14, Taiwanese version-revised (DS14-TR), ${ }^{2,29}$ which consists of two 7-item subscales to measure NA and SI, respectively. Items are scored on a 5-point Likert scale ranging from 0 (false) to 4 (true), with a total subscale 
score ranging from 0 and 28. TDP is determined while both subscales score 10 points or higher. Both subscales have been tested previously to be internally consistent (Cronbach's $\alpha=0.87$ and 0.83 for NA and SI, respectively) on T2DM patients. ${ }^{11}$

\section{Self-Efficacy}

We used the Chinese Version of Diabetes Management SelfEfficacy Scale (C-DMSES), developed by Vivienne Wu et $\mathrm{al}^{30}$ in 2008. It contains 20 items that reflect the multiple aspects of self-efficacy on diabetes patients, including diet control, physical activity, symptom management, and role function. Each item is on a score from 0 (no confidence at all) to 10 (full confidence), with a total score between 0 and 200. The total score of the 20 items indicates the level of self-efficacy. A higher score reflects better self-efficacy. The Cronbach's $\alpha$ value of the scale has been previously estimated at $0.95 .^{30}$

\section{Self-Care Behaviors}

We used the Chinese Version of Diabetes Self-Care Scale (C-DSC), designed by Hurley et $\mathrm{al}^{31}$ in 1992 and modified by Wang et $\mathrm{al}^{32}$ in 1998 , to assess five domains of a patient's self-care behaviors to manage diabetes, which includes diet control, physical activity, medication compliance and glucose monitoring, prevention of diabetic foot, and treatment of hyper/hypo-glycemia. It contains 26 items and each item is scored on a 5-point Likert scale from 1 (totally disagree) to 5 (totally agree), with a total score between 26 and 130. A higher score indicates better self-care behaviors. The Cronbach's $\alpha$ value of the scale is between 0.82 and $0.92 .^{32}$

\section{Perceived Stress}

We used the Chinese Version of Problem Area in Diabetes (PAID-C), designed by Polonsky et $\mathrm{al}^{33}$ in 1995 and modified by Huang et $\mathrm{al}^{34}$ in 2010 , to measure a patient's perceived stress about T2DM. It contains 20 items, covering the emotional burden of diabetes and the accumulated strains from treatment and medical adherence. Each item is scored on a 5-point Likert scale from 0 (no problem at all) to 4 (severe problem), with a total score between 0 and 80. A higher score indicates a patient perceiving more diabetes-related stress. The Cronbach's $\alpha$ value of the scale is between 0.83 and $0.95 .^{34}$

\section{Psychological Distress (Anxiety and Depression)}

We used the Chinese Version of Hospital Anxiety and Depression Scale (C-HADS), developed by Zigmond et al35 in 1983, translated and validated by Leung et $\mathrm{al}^{36}$ in 1993 and Wang et $\mathrm{al}^{37}$ in 2009 , to identify the two most common forms of psychological distress (anxiety and depression) on T2DM patients. The scale consists of two 7-item subscales of anxiety and depression, respectively. Each item is scored on a 4-point Likert scale and the total score of the 14 items indicates the severity of psychological distress (scores: 0-7 normal; 8-10 mild; 11-14 moderate; $15-21$ severe). The Cronbach's $\alpha$ of the scale on T2DM patients is between 0.76 and $0.81 .^{38}$

\section{Statistical Analysis}

The data were collected and entered into the computer by the sole trained hospital staff. The Cronbach's $\alpha$ values were calculated to assess the internal consistency of these scales. Numeric values were presented as mean \pm standard deviation (SD), with categorical values as $\mathrm{n}(\%)$. The differences in the demographic and socioeconomic characteristics between T2DM patients with TDP and non-TDP were compared by the independent sample $t$-test (for continuous variables) and the chisquare test (for categorical variables). The associations of TDP and psychological variables of T2DM were tested by Bi-serial correlation and Pearson productmoment correlation. A $P$-value of $<0.05$ was considered statistically significant. All statistical analysis was performed by the SPSS statistical software (version 22.0, IBM Corp., Armonk, NY, USA).

\section{Results}

There were $198 \mathrm{~T} 2 \mathrm{DM}$ patients (male 62.6\%, mean age $51.2 \pm 11.0$, mean HbAlc $7.3 \pm 1.8 \%$ ) enrolled in the study. Eighty-two (41.4\%) of them had TDP. Table 1 is the demographic, social, and clinical characteristics of the participant with and without TDP. There were no significant differences between the two groups in the distributions of gender, age, body mass index (BMI), T2DM duration, smoking/drinking history, education level, marital status, employment status, current treatment, and major complications. It was important to note that the group with TDP had significantly higher percentage in numbers of high HbA1c level than the non-TDP, which 
Table I Demographic, Social, and Clinical Characteristics of the Participants with and Without Type D Personality (TDP): The Group with TDP Had Significantly Higher Percentage in Numbers of High HbAlc Level Than the Non-TDP, Which Indicated That TDP Had Poorer Glycemic Control Than Non-TDP

\begin{tabular}{|c|c|c|c|c|c|}
\hline Variables & $\begin{array}{l}\text { Total } \\
n=198\end{array}$ & $\begin{array}{l}\text { TDP } \\
n=82 \text { (4I.4\%) }\end{array}$ & $\begin{array}{l}\text { Non-TDP } \\
n=116 \text { (58.6\%) }\end{array}$ & Test & Effect Sizes \\
\hline Gender (male, n,\%) & $124(62.6 \%)$ & $50(60.1 \%)$ & $74(63.8 \%)$ & \multirow{8}{*}{$\begin{array}{l}\text { Fisher's test, } P=0.766 \\
\chi^{2}=6.31 \\
P=0.280\end{array}$} & \multirow{8}{*}{$\begin{array}{l}\mathrm{OR}(95 \% \mathrm{Cl})=0.89(0.49-1.59) \\
\text { Hedges' } \mathrm{g}=0.17\end{array}$} \\
\hline Age $(n, \%)$ & $51.2 \pm 11.0$ & $50.0 \pm 12.1$ & $52.0 \pm 11.3$ & & \\
\hline $20-30$ & $3(1.5 \%)$ & $\mathrm{I}(\mathrm{I} .2 \%)$ & $2(1.7 \%)$ & & \\
\hline $31-40$ & $18(9.1 \%)$ & II(I3.4\%) & $7(6.0 \%)$ & & \\
\hline $41-50$ & $64(32.3 \%)$ & $25(30.5 \%)$ & $39(33.6 \%)$ & & \\
\hline $51-60$ & $84(42.4 \%)$ & $36(43.9 \%)$ & $48(41.4 \%)$ & & \\
\hline $61-70$ & $25(12.6 \%)$ & $9(11.0 \%)$ & $16(13.8 \%)$ & & \\
\hline $7 \mid-80$ & $4(2.0 \%)$ & $0(0.0 \%)$ & $4(3.4 \%)$ & & \\
\hline BMI $(n, \%)$ & $26.7 \pm 4.6$ & $27.0 \pm 4.9$ & $26.5 \pm 4.3$ & \multirow{4}{*}{$\begin{array}{l}t=0.815 \\
P=0.416\end{array}$} & \multirow[t]{4}{*}{ Hedges' $g=0.11$} \\
\hline Normal (I8.5-23.9) & $59(29.8 \%)$ & $24(29.3 \%)$ & $35(30.2 \%)$ & & \\
\hline Overweight (24-26.9) & $56(28.3 \%)$ & $20(24.4 \%)$ & $36(31.0 \%)$ & & \\
\hline Obese $(\geq 27)$ & $83(41.9 \%)$ & $38(46.3 \%)$ & $45(38.8 \%)$ & & \\
\hline HbAlc (n,\%) & $7.3 \pm 1.8$ & $7.6 \pm 1.9$ & $7.1 \pm 1.8$ & \multirow{6}{*}{$\begin{array}{l}\chi^{2}=9.494 \\
P<0.05 *\end{array}$} & \multirow[t]{6}{*}{ Cramer's $V=0.22$} \\
\hline$\leq 7 \%$ & $98(49.5 \%)$ & $38(46.3 \%)$ & $60(51.7 \%)$ & & \\
\hline $7.1-8 \%$ & $67(33.8 \%)$ & $25(30.5 \%)$ & $42(36.2 \%)$ & & \\
\hline $8.1-9 \%$ & $20(10.1 \%)$ & $12(14.6 \%)$ & $8(6.9 \%)$ & & \\
\hline $9.1-10 \%$ & $9(4.5 \%)$ & $3(3.7 \%)$ & $6(5.2 \%)$ & & \\
\hline$\geq 10 \%$ & $4(2.0 \%)$ & $4(4.9 \%)$ & $0(0.0 \%)$ & & \\
\hline T2DM duration $(\mathrm{n}, \%)$ & & & & \multirow{6}{*}{$\begin{array}{l}\chi^{2}=6.441 \\
P=0.169\end{array}$} & \multirow[t]{6}{*}{ Cramer's $V=0.18$} \\
\hline Under 6 months & $15(7.6 \%)$ & $5(6.1 \%)$ & $10(8.6 \%)$ & & \\
\hline $6-12$ months & $28(14.1 \%)$ & $1 \mathrm{I}(13.4 \%)$ & $17(14.7 \%)$ & & \\
\hline $1-5$ years & $86(43.4 \%)$ & $34(41.5 \%)$ & $52(44.8 \%)$ & & \\
\hline $5-10$ years & $38(19.2 \%)$ & $13(15.9 \%)$ & $25(21.6 \%)$ & & \\
\hline Above 10 years & $31(15.7 \%)$ & $19(23.2 \%)$ & $12(10.3 \%)$ & & \\
\hline Smokers (n,\%) & $28(14.1 \%)$ & $\mathrm{II}(13.4 \%)$ & $17(14.7 \%)$ & $\begin{array}{l}\text { Fisher's test, } \\
P=0.839\end{array}$ & $\mathrm{OR}(95 \% \mathrm{Cl})=0.90(0.40-2.04)$ \\
\hline Drinkers (n,\%) & $18(9.1 \%)$ & $8(9.8 \%)$ & $10(8.6 \%)$ & $\begin{array}{l}\text { Fisher's test, } \\
P=0.522\end{array}$ & $\mathrm{OR}(95 \% \mathrm{Cl})=1.15(0.43-3.04)$ \\
\hline Educational level (n,\%) & & & & $\mathrm{t}=-1.702$ & $\mathrm{OR}(95 \% \mathrm{Cl})=1.30(0.74-2.30)$ \\
\hline High school or lower & $97(49.0 \%)$ & $37(45.1 \%)$ & $60(51.7 \%)$ & $P=0.090$ & \\
\hline University/college or higher & $101(51.0 \%)$ & $45(54.9 \%)$ & $56(48.3 \%)$ & & \\
\hline Marital status (n,\%) & & & & $\chi^{2}=6.34$ & Cramer's $V=0.19$ \\
\hline Unmarried & $37(18.7 \%)$ & $21(25.6 \%)$ & $16(13.8 \%)$ & $P=0.100$ & \\
\hline Married & $147(74.2 \%)$ & $55(67.1 \%)$ & $92(79.3 \%)$ & & \\
\hline Divorce & $12(6.1 \%)$ & $6(7.3 \%)$ & $6(5.2 \%)$ & & \\
\hline Widowed & $2(1.0 \%)$ & $0(0.0 \%)$ & $2(1.7 \%)$ & & \\
\hline Employment status (n,\%) & & & & $\chi^{2}=8.40$, & Cramer's V $=0.21$ \\
\hline Unemployed & $6(3.0 \%)$ & $2(2.4 \%)$ & $4(3.4 \%)$ & $P=0.490$ & \\
\hline Student & $2(1.0 \%)$ & $0(0.0 \%)$ & $2(1.7 \%)$ & & \\
\hline Government employee & $17(8.6 \%)$ & $5(6.1 \%)$ & $12(10.3 \%)$ & & \\
\hline Labor & $26(13.1 \%)$ & $8(9.8 \%)$ & $18(15.5 \%)$ & & \\
\hline Business & $59(29.8 \%)$ & $27(32.9 \%)$ & $32(27.6 \%)$ & & \\
\hline Service industry & $62(31.3 \%)$ & $31(37.8 \%)$ & $3 \mathrm{I}(26.7 \%)$ & & \\
\hline Medical industry & $4(2.0 \%)$ & $2(2.4 \%)$ & $2(1.7 \%)$ & & \\
\hline Freelance & $10(5.1 \%)$ & $4(4.9 \%)$ & $6(5.2 \%)$ & & \\
\hline Homemaker & $7(3.5 \%)$ & $\mathrm{I}(\mathrm{I} .2 \%)$ & $6(5.2 \%)$ & & \\
\hline Other & $5(2.5 \%)$ & $2(2.4 \%)$ & $3(2.6 \%)$ & & \\
\hline
\end{tabular}

(Continued) 
Table I (Continued).

\begin{tabular}{|c|c|c|c|c|c|}
\hline Variables & $\begin{array}{l}\text { Total } \\
n=198\end{array}$ & $\begin{array}{l}\text { TDP } \\
n=82(41.4 \%)\end{array}$ & $\begin{array}{l}\text { Non-TDP } \\
n=116(58.6 \%)\end{array}$ & Test & Effect Sizes \\
\hline $\begin{array}{l}\text { Current treatment }(\mathrm{n}, \%) \\
\text { Only diet and exercise } \\
\text { Only OADs } \\
\text { Only Insulin/GLP-I RA } \\
\text { OADs+Insulin/GLP-I RA } \\
\text { No treatment }\end{array}$ & $\begin{array}{l}18(9.1 \%) \\
55(27.8 \%) \\
10(5.1 \%) \\
114(57.5 \%) \\
1(0.5 \%)\end{array}$ & $\begin{array}{l}7(8.5 \%) \\
25(30.5 \%) \\
6(7.3 \%) \\
44(53.7 \%) \\
0(0.0 \%)\end{array}$ & $\begin{array}{l}\text { II (9.5\%) } \\
30(25.9 \%) \\
4(3.4 \%) \\
70(60.3 \%) \\
I(0.9 \%)\end{array}$ & $\begin{array}{l}\chi^{2}=2.921, \\
P=0.571\end{array}$ & Cramer's $V=0.12$ \\
\hline $\begin{array}{l}\text { Major complications } \\
\text { None } \\
\text { Retinopathy } \\
\text { Nephropathy } \\
\text { Neuropathy } \\
\text { Cardiopathy } \\
\text { Other }\end{array}$ & $\begin{array}{l}175(88.4 \%) \\
15(7.6 \%) \\
2(1.0 \%) \\
1(0.5 \%) \\
3(1.5 \%) \\
2(1.0 \%)\end{array}$ & $\begin{array}{l}68(82.9 \%) \\
8(9.8 \%) \\
2(2.4 \%) \\
I(1.2 \%) \\
2(2.4 \%) \\
I(1.2 \%)\end{array}$ & $\begin{array}{l}107(92.2 \%) \\
7(6.0 \%) \\
0(0.0 \%) \\
0(0.0 \%) \\
I(0.9 \%) \\
I(0.9 \%)\end{array}$ & $\begin{array}{l}\chi^{2}=6.443 \\
P=0.265\end{array}$ & Cramer's $V=0.18$ \\
\hline
\end{tabular}

Notes: Values are mean \pm standard deviation or $n(\%)$. $P$-value: TDP vs non-TDP. $* P<0.05$ is statistically significant.

Abbreviations: TDP, Type D personality; T2DM, type 2 diabetes mellitus; HbAIc, glycosylated hemoglobin; BMI, body mass index; OAD, oral antidiabetic drug; GLP-I RA, glucagon-like peptide-I receptor agonist.

indicated that TDP had poorer glycemic control than nonTDP (mean HbA1c (\%) $7.6 \pm 1.9$ vs $7.1 \pm 1.8, P<0.05)$.

Table 2 shows the comparisons of the perceived stress, self-efficacy, self-care behaviors, and psychological distress scores on T2DM patients with and without TDP. TDP had significantly higher scores on perceived stress $(P<0.001)$ and psychological distress $(P<0.001)$, but who had significantly lower scores on self-efficacy $(P<0.001)$ and self-care behaviors $(P<0.001)$ than non-TDP.

Table 3 presents the correlations between TDP, perceived stress, self-efficacy, self-care behaviors, and psychological distress scores on T2DM patients. TDP had significantly positive correlations with perceived stress and psychological distress, but it had significantly negative

Table 2 Comparisons of the Perceived Stress, Self-Efficacy, Self-Care Behaviors, and Psychological Distress Scores on T2DM Patients with and Without Type D Personality (TDP): TDP Had Significantly Higher Scores on Perceived Stress and Psychological Distress, but Who Had Significantly Lower Scores on Self-Efficacy and Self-Care Behaviors Than Non-TDP

\begin{tabular}{|c|c|c|c|c|}
\hline Variables & $\begin{array}{l}\text { TDP } \\
n=82\end{array}$ & $\begin{array}{l}\text { Non-TDP } \\
n=1 / 6\end{array}$ & $\begin{array}{l}\text { Test } \\
\text { t/F }\end{array}$ & Hedges' g \\
\hline Perceived stress & $29.4 \pm 12.4$ & $15.1 \pm 10.4$ & $-8.797 * * *$ & 1.27 \\
\hline Total self-efficacy(SE) & $134.6 \pm 26.9$ & $156.9 \pm 28.9$ & $5.522 * * *$ & 0.79 \\
\hline Dietary SE & $53.1 \pm 13.8$ & $65.2 \pm 16.5$ & $29.774 * * *$ & 0.78 \\
\hline Physical activity and weight control SE & $25.4 \pm 7.4$ & $30.1 \pm 7.2$ & $20.788 * * *$ & 0.65 \\
\hline Compliance SE & $26.5 \pm 4.0$ & $28.1 \pm 3.0$ & $9.665 * *$ & 0.46 \\
\hline Blood glucose and foot monitor SE & $29.6 \pm 6.9$ & $33.5 \pm 6.0$ & $17.972 * * *$ & 0.61 \\
\hline Total self-care behavior (SC) & $82.5 \pm 16.4$ & $93.2 \pm 18.8$ & $4.166 * * *$ & 0.60 \\
\hline Dietary SC & $18.2 \pm 5.2$ & $21.2 \pm 5.5$ & $15.497^{* * *}$ & 0.56 \\
\hline Physical activity SC & $10.8 \pm 4.2$ & $12.4 \pm 5.1$ & $5.703 *$ & 0.34 \\
\hline Higher or lower blood glucose prevention and treatment SC & $15.4 \pm 5.4$ & $18.3 \pm 5.3$ & $13.846 * *$ & 0.54 \\
\hline Medical and blood glucose monitor SC & $22.9 \pm 5.4$ & $25.1 \pm 6.3$ & $6.479 *$ & 0.37 \\
\hline Foot-care SC & $15.3 \pm 3.5$ & $16.3 \pm 3.5$ & $3.88 I^{*}$ & 0.29 \\
\hline Psychological distress & $12.4 \pm 4.8$ & $6.0 \pm 4.2$ & $-9.961 * * *$ & 1.44 \\
\hline Anxiety & $7.0 \pm 2.9$ & $3.5 \pm 2.7$ & $72.772 * * *$ & 1.23 \\
\hline Depression & $5.4 \pm 2.9$ & $2.5 \pm 2.2$ & $66.186 * * *$ & 1.15 \\
\hline
\end{tabular}

Notes: Data presented as mean \pm standard deviation. $* P<0.05, * * P<0.01$, and $* * * P<0.001$ are statistically significant.

Abbreviations: TDP, Type D personality; SE, self-efficacy; SC, self-care behavior; T2DM, type 2 diabetes mellitus. 


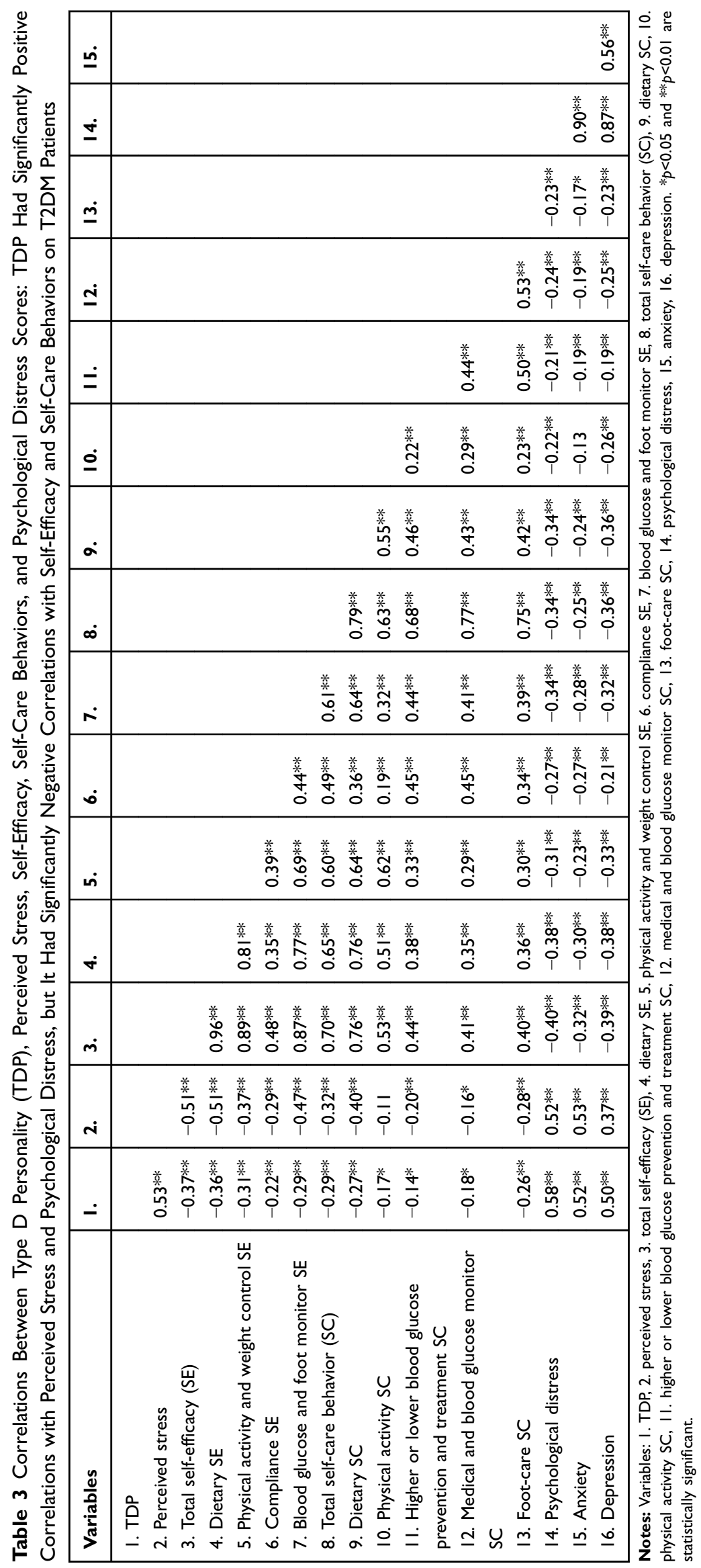


correlations with self-efficacy and self-care behaviors. Additionally, self-efficacy positively correlated with selfcare behaviors. Psychological distress positively correlated with perceived stress, but negatively correlated with selfefficacy and self-care behaviors.

\section{Discussion}

In our study, $82(41.4 \%)$ of the 198 T2DM patients had TDP. The rate is higher than previously reported on Dutch adults with T2DM $(28.1 \%)^{11}$ and Chinese adults with T2DM $(27.9 \%) .{ }^{15}$ It may be because that the T2DM patients in our study were mostly middle aged (51.2 \pm 11.0 ) with high educational levels (University/college or higher 51\%), which led them to express more health awareness and attitudes through these questionnaires.

As shown in Table 1, the demographic and social characteristics had no difference between TDP and nonTDP, which was consistent with the previous reports. ${ }^{1-3,12}$ Importantly, we found that HbAlc levels were significantly higher on the patients with TDP than those with non-TDP, which was consistent with the studies by $\mathrm{Li}$ $\mathrm{X}$ et $\mathrm{al}^{16}$ and Shao $\mathrm{Y}$ et al. ${ }^{17}$ Therefore, T2DM patients with TDP tend to have poor glycemic control.

As shown in Table 2, T2DM patients with TDP had significantly higher scores on perceived stress and psychological distress (anxiety and depression), but who had significantly lower scores on self-efficacy (including dietary, physical activity and weight control, compliance, and blood glucose and foot monitor) and on self-care behaviors (including dietary, physical activity, higher or lower blood glucose prevention and treatment, medical and blood glucose monitor, and foot-care). These findings implicated that T2DM patients with TDP were more likely to perceive more diabetes-related stress, to experience more psychological distresses, and to have lower levels of selfefficacy and self-care behaviors to manage their diabetes. Our findings were consistent with the several previous studies, which reported that TDP was easy to have an increased number of severity of reported health complaints, heightened the perception of negative emotions (eg, depression and anxiety), an adverse effect on healthrelated behaviors, poor adherence to treatment, and less likely to perform a regular medical checkup, so that TDP is associated with unhealthy lifestyle, poor physical and mental health status, poor self-efficacy, and poor self-care behaviors of the disease. ${ }^{11,17,39,40}$

As shown in Table 3, TDP had significantly positive correlations with perceived stress and psychological distress. It had significantly negative correlations with selfefficacy and self-care behaviors on T2DM patients. Our findings were consistent with the several previous studies $^{41-46}$ and highlighted these plausible biological and behavioral interactions that may explain the poor health outcome of Type D personality on T2DM patients. TDP plays an important role in self-efficacy, self-care behaviors, perceived stress and psychological distress on T2DM patients.

Despite the growing body of evidences reporting the disadvantages of TDP in patients with diabetes, the effects of TDP have received relatively little attention either to researches or to clinical practice of diabetes care. Our study emphasized the evidence linking TDP with poor glycemic control, low levels of self-efficacy and self-care behaviors, as well as high levels of perceived stress and psychological distress. TDP might be considered to need tailored interventions of these aspects for diabetes care.

Although beyond the scope of the present investigation, the emerging issue of euthymia has been considered as a clinical factor that may affect the positive mental health of patients with diabetes. It is worth investigating euthymia as a tool, as well as a target, for diabetes care in the future. $^{47,48}$

There were some limitations in our study. Firstly, the sample was small, which was random sampling and collected from the endocrine clinic outpatient visits of a single hospital, that cannot be either directly generalized as the normal population with T2DM or those with more complicated comorbidities. Secondly, our design of study was cross-sectional and self-reported. Our findings may have subjective reporting biases.

\section{Conclusion}

Our study provided the evidence linking TDP with poor glycemic control, low levels of self-efficacy and self-care behaviors, as well as high levels of perceived stress and psychological distress. We suggested that it might be necessary not only to have TDP screening mechanism among T2DM in place, but also tailored interventions of these aspects for diabetes care.

\section{Abbreviations}

TDP, Type D personality; T2DM, type 2 diabetes mellitus; HbA1c, glycosylated hemoglobin; BMI, body mass index; OAD, oral antidiabetic drug; GLP-1 RA, glucagon-like peptide-1 receptor agonist; SE, self-efficacy; SC, self-care behavior; NA, negative affectivity; SI, social inhibition. 


\section{Data Sharing Statement}

The datasets generated and analysed during the current study are not publicly available due to personal privacy but are available from the corresponding author on reasonable request.

\section{Ethics and Consent Statement}

The Taiwan Adventist Hospital Ethics Committee approved this study (106-E-26). All participants gave written informed consent before data collection began. Consent for publication: All participants gave written informed consent for publication.

\section{Acknowledgments}

The authors would like to thank all the people with T2DM who participated in this study. The authors also are grateful to the hospital officials for providing support for this study and Sabina Wang for revision of the English.

\section{Author Contributions}

All authors made substantial contributions to conception and design, acquisition of data, or analysis and interpretation of data; took part in drafting the article or revising it critically for important intellectual content; gave final approval of the version to be published; and agree to be accountable for all aspects of the work.

\section{Funding}

The work was supported by Department of Education and Research, Taiwan Adventist Hospital.

\section{Disclosure}

The authors report no conflicts of interest in this work.

\section{References}

1. Denollet J. Type D personality. A potential risk factor refined. J Psychosom Res. 2000;49(4):255-266. doi:10.1016/S0022-3999(00) 00177-X

2. Denollet J. DS14: standard assessment of negative affectivity, social inhibition, and Type D personality. Psychosom Med. 2005;67 (1):89-97. doi:10.1097/01.psy.0000149256.81953.49

3. Schiffer AA, Smith OR, Pedersen SS, Widdershoven JW, Denollet J. Type D personality and cardiac mortality in patients with chronic heart failure. Int $J$ Cardiol. 2010;142(3):230-235. doi:10.1016/j. ijcard.2008.12.090

4. Denollet J, Sys SU, Stroobant N, Rombouts H, Gillebert TC, Brutsaert DL. Personality as independent predictor of long-term mortality in patients with coronary heart disease. Lancet. 1996;347 (8999):417-421. doi:10.1016/S0140-6736(96)90007-0

5. Chapman BP, Duberstein PR, Lyness JM. The distressed personality type: replicability and general health associations. Eur J Pers. 2007;21 (7):911-929. doi:10.1002/per.645
6. Martens EJ, Mols F, Burg MM, Denollet J. Type D personality predicts clinical events after myocardial infarction, above and beyond disease severity and depression. J Clin Psychiatry. 2010;71 (06):778-783. doi:10.4088/JCP.08m04765blu

7. Denollet J, Pedersen SS, Vrints CJ, Conraads VM. Predictive value of social inhibition and negative affectivity for cardiovascular events and mortality in patients with coronary artery disease: the Type D personality construct. Psychosom Med. 2013;75(9):873-881. doi:10.1097/PSY.0000000000000001

8. Vukovic O, Tosevski DL, Jasovic-Gasic M, et al. Type D personality in patients with coronary artery disease. Psychiatr Danub. 2014;26 (1):46-51.

9. Conti C, Carrozzino D, Patierno C, Vitacolonna E, Fulcheri M. The clinical link between Type D personality and diabetes. Front Psychiatry. 2016;7:113. doi:10.3389/fpsyt.2016.00113

10. Zamani-Alavijeh F, Araban M, Koohestani HR, Karimy M. The effectiveness of stress management training on blood glucose control in patients with type 2 diabetes. Diabetol Metab Syndr. 2018;10 (1):39. doi:10.1186/s13098-018-0342-5

11. Nefs G, Speight J, Pouwer F, Pop V, Bot M, Denollet J. Type D personality, suboptimal health behaviors and emotional distress in adults with diabetes: results from diabetes MILES-The Netherlands. Diabetes Res Clin Pract. 2015;108(1):94-105. doi:10.1016/j. diabres.2015.01.015

12. Nefs G, Pouwer F, Pop V, Denollet J. Type D (distressed) personality in primary care patients with type 2 diabetes: validation and clinical correlates of the DS14 assessment. J Psychosom Res. 2012;72 (4):251-257. doi:10.1016/j.jpsychores.2012.01.006

13. Nefs G, Pouwer F, Denollet J, Pop V. The course of depressive symptoms in primary care patients with type 2 diabetes: results from the diabetes, depression, Type D personality zuidoost-brabant (DiaDDZoB) study. Diabetologia. 2012;55(3):608-616. doi:10.1007/ s00125-011-2411-2

14. Milicevic R, Jaksic N, Aukst-Margetic B, Jakovljevic M. Personality traits and treatment compliance in patients with type 2 diabetes mellitus. Psychiatr Danub. 2015;27 Suppl 2:586-589.

15. Li X, Zhang S, Xu H, et al. Type D personality predicts poor medication adherence in Chinese patients with type 2 diabetes mellitus: a six-month follow-up study. PLoS One. 2016;11(2):e0146892. doi:10.1371/journal.pone.0146892

16. Li X, Gao M, Zhang S, et al. Medication adherence mediates the association between Type D personality and high HbAlc level in Chinese patients with type 2 diabetes mellitus: a six-month follow-up study. J Diabetes Res. 2017;2017:7589184. doi:10.1155/2017/ 7589184

17. Shao Y, Yin H, Wan C. Type D personality as a predictor of self-efficacy and social support in patients with type 2 diabetes mellitus. Neuropsychiatr Dis Treat. 2017;13:855-861. doi:10.2147/ NDT.S128432

18. Conti C, Di Francesco G, Fontanella L, et al. Negative affectivity predicts lower quality of life and metabolic control in type 2 diabetes patients: a structural equation modeling approach. Front Psychol. 2017;8:831. doi:10.3389/fpsyg.2017.00831

19. Bandura A. Health promotion from the perspective of social cognitive theory. Psychol Health. 1998;13(4):623-649. doi:10.1080/ 08870449808407422

20. Al-Khawaldeh OA, Al-Hassan MA, Froelicher ES. Self-efficacy, self-management, and glycemic control in adults with type 2 diabetes mellitus. J Diabetes Complications. 2012;26(1):10-16. doi:10.1016/j. jdiacomp.2011.11.002

21. Lee EH, Lee YW, Moon SH. A structural equation model linking health literacy to self-efficacy, self-care activities, and health-related quality of life in patients with type 2 diabetes. Asian Nurs Res (Korean Soc Nurs Sci). 2016;10(1):82-87. doi:10.1016/j. anr.2016.01.005 
22. Cherrington A, Wallston KA, Russell L, Rothman RL. Exploring the relationship between diabetes self-efficacy, depressive symptoms, and glycemic control among men and women with type 2 diabetes. $J$ Behav Med. 2010;33(1):81-89. doi:10.1007/s10865-009-9233-4

23. Ali S, Stone MA, Peters JL, Davies MJ, Khunti K. The prevalence of co-morbid depression in adults with type 2 diabetes: a systematic review and meta-analysis. Diabet Med. 2006;23(11):1165-1173. doi:10.1111/j.1464-5491.2006.01943.x

24. Bener A, Al-Hamaq AOAA, Dafeeah EE. High prevalence of depression, anxiety and stress symptoms among diabetes mellitus patients. Open Psychiatr J. 2011;5(1):5-12. doi:10.2174/1874354401105010005

25. Ogbera A, Adeyemi-Doro A. Emotional distress is associated with poor self care in type 2 diabetes mellitus. J Diabetes. 2011;3 (4):348-352. doi:10.1111/j.1753-0407.2011.00156.x

26. Indelicato L, Dauriz M, Santi L, et al. Psychological distress, self-efficacy and glycemic control in type 2 diabetes. Nutr Metab Cardiovasc Dis. 2017;27(4):300-306. doi:10.1016/j.numecd. 2017.01.006

27. Schinckus L, Dangoisse F, Van den Broucke S, Mikolajczak M. When knowing is not enough: emotional distress and depression reduce the positive effects of health literacy on diabetes self-management. Patient Educ Couns. 2018;101(2):324-330. doi:10.1016/j.pec.2017.08.006

28. Surwit RS, van Tilburg MA, Zucker N, et al. Stress management improves long-term glycemic control in type 2 diabetes. Diabetes Care. 2002;25(1):30-34. doi:10.2337/diacare.25.1.30

29. Weng CY, Denollet J, Lin CL, et al. The validity of the Type $\mathrm{D}$ construct and its assessment in Taiwan. BMC Psychiatry. 2013;13(1):46. doi:10.1186/1471-244X-13-46

30. Vivienne Wu SF, Courtney M, Edwards H, McDowell J, ShortridgeBaggett LM, Chang PJ. Development and validation of the Chinese version of the diabetes management self-efficacy scale. Int J Nurs Stud. 2008;45(4):534-542. doi:10.1016/j.ijnurstu.2006.08.020

31. Hurley AC, Shea CA. Self-efficacy: strategy for enhancing diabetes self-care. Diabetes Educ. 1992;18(2):146-150. doi:10.1177/0145721 79201800208

32. Wang JS, Wang RH, Lin CC. Self-care behaviors, self-efficacy, and social support effect on the glycemic control of patients newly diagnosed with non-insulin-dependent diabetes mellitus. Kaohsiung $J$ Med Sci. 1998;14(12):807-815.

33. Polonsky WH, Anderson BJ, Lohrer PA, et al. Assessment of diabetes-related distress. Diabetes Care. 1995;18(6):754-760. doi:10.2337/diacare.18.6.754

34. Huang MF, Courtney M, Edwards H, McDowell J. Validation of the Chinese version of the Problem Areas in Diabetes (PAID-C) scale. Diabetes Care. 2010;33(1):38-40. doi:10.2337/dc09-0768

35. Zigmond AS, Snaith RP. The hospital anxiety and depression scale. Acta Psychiatr Scand. 1983;67(6):361-370. doi:10.1111/j.16000447.1983.tb09716.x
36. Leung CM, Ho S, Kan CS, Hung CH, Chen CN. Evaluation of the Chinese version of the hospital anxiety and depression scale. A cross-cultural perspective. Int J Psychosom. 1993;40(1-4):29-34.

37. Wang W, Chair SY, Thompson DR, Twinn SF. A psychometric evaluation of the Chinese version of the hospital anxiety and depression scale in patients with coronary heart disease. J Clin Nurs. 2009;18(13):1908-1915. doi:10.1111/j.1365-2702.2008.02736.x

38. Pais-Ribeiro J, Silva I, Ferreira T, Martins A, Meneses R, Baltar M. Validation study of a Portuguese version of the hospital anxiety and depression scale. Psychol Health Med. 2007;12(2):225-237. doi:10. 1080/13548500500524088

39. Mols F, Denollet J. Type D personality among noncardiovascular patient populations: a systematic review. Gen Hosp Psychiatry. 2010;32(1):66-72. doi:10.1016/j.genhosppsych.2009.09.010

40. Mommersteeg PM, Kupper N, Denollet J. Type D personality is associated with increased metabolic syndrome prevalence and an unhealthy lifestyle in a cross-sectional Dutch community sample. BMC Public Health. 2010;10(1):714. doi:10.1186/1471-2458-10-714

41. Denollet J, Schiffer AA, Spek V. A general propensity to psychological distress affects cardiovascular outcomes: evidence from research on the type D (distressed) personality profile. Circ Cardiovasc Qual Outcomes. 2010;3(5):546-557. doi:10.1161/ CIRCOUTCOMES.109.934406

42. Molloy GJ, Randall G, Wikman A, Perkins-Porras L, MesserliBürgy N, Steptoe A. Type D personality, self-efficacy, and medication adherence following an acute coronary syndrome. Psychosom Med. 2012;74(1):100-106. doi:10.1097/PSY.0b013e31823a5b2f

43. Williams L, Wingate A. Type D personality, physical symptoms and subjective stress: the mediating effects of coping and social support. Psychol Health. 2012;27(9):1075-1085. doi:10.1080/08870446. 2012.667098

44. Booth L, Williams L. Type D personality and dietary intake: the mediating effects of coping style. J Health Psychol. 2015;20 (6):921-927. doi:10.1177/1359105315573433

45. Ginting H, van de Ven M, Becker ES, Näring G. Type D personality is associated with health behaviors and perceived social support in individuals with coronary heart disease. J Health Psychol. 2016;21 (5):727-737. doi:10.1177/1359105314536750

46. Williams L, Abbott C, Kerr R. Health behaviour mediates the relationship between Type D personality and subjective health in the general population. $J$ Health Psychol. 2016;21(10):2148-2155. doi:10.1177/1359105315571977

47. Carrozzino D, Svicher A, Patierno C, Berrocal C, Cosci F. The euthymia scale: a clinimetric analysis. Psychother Psychosom. 2019;88(2):119-121. doi:10.1159/000496230

48. Kalra S, Balhara YPS, Bathla M. Euthymia in diabetes. Eur Endocrinol. 2018;14(2):18-19. doi:10.17925/EE.2018.14.2.18
Psychology Research and Behavior Management

Publish your work in this journal

Psychology Research and Behavior Management is an international, peer-reviewed, open access journal focusing on the science of psychology and its application in behavior management to develop improved outcomes in the clinical, educational, sports and business arenas. Specific topics covered in the journal include: Neuroscience, memory and decision making; Behavior modification and management; Clinical applications; Business and sports performance management; Social and developmental studies; Animal studies. The manuscript management system is completely online and includes a very quick and fair peer-review system, which is all easy to use. Visit http://www. dovepress.com/testimonials.php to read real quotes from published authors. 